\title{
Acute Kidney Injury in Patients with Acute Coronary Syndrome after Percutaneous Coronary Intervention: Pathophysiologies, Risk Factors, and Preventive Measures
}

\author{
Ya-feng Zhang ${ }^{a}$ Da-dong Liu ${ }^{b}$ Yue Zhou ${ }^{c}$ Ji-zhuang Lou ${ }^{c}$ \\ aDepartment of Healthcare-associated Infection Management, Affiliated Hospital of Jiangsu University, Zhenjiang, \\ China; ${ }^{b}$ Department of Critical Care Medicine, Affiliated Hospital of Jiangsu University, Zhenjiang, China; \\ 'Department of Blood Purification Center, Nanjing First Hospital, Nanjing Medical University, Nanjing, China
}

\section{Keywords}

Acute kidney injury - Percutaneous coronary intervention · Acute coronary syndrome

\begin{abstract}
Absrtact
Background: Percutaneous coronary intervention ( $\mathrm{PCl}$ ) has been an effective treatment for acute coronary syndrome (ACS) patients. Acute kidney injury (AKI) is one of the common complications after $\mathrm{PCl}$, which seriously affects the living quality and survival time of patients. The approach followed for the patient with AKI after PCl depends on the clinical context and may vary by resource availability. Summary: This review focuses on the pathophysiologies, influencing factors, and preventive measures of AKI in patients with ACS after $\mathrm{PCl}$. The knowledge may better serve the patients and improve their outcomes. Key Messages: Many studies have been carried out for the definition and standard of AKI in the past few years. Etiologies of AKI after PCl included renal damage of contrast medium and atherosclerotic embolism, cardiac insufficiency and surgical factors on renal function. Basic conditions, treatment modalities, and perioperative changes are major risk factors of AKI. Studies have reported that the prevention of contrast-induced nephropathy, mod-
\end{abstract}

karger@karger.com

(c) 2021 S. Karger AG, Basel

www.karger.com/crd

Karger" ulating the volume overload, some pharmaceuticals and blood purification treatment are helpful to prevent the occurrence of AKI.

(c) 2021 S. Karger AG, Basel

\section{Introduction}

Acute coronary syndrome (ACS) is a serious type of coronary heart disease with increasing morbidity, and the mortality ranking first in the current noninfectious diseases [1]. With the advent of the era of medical reperfusion, percutaneous coronary intervention (PCI) has being an effective treatment for ACS patients. Acute kidney injury (AKI) is one of the common complications after PCI. A large-sample retrospective cohort study in the USA showed that the incidence of AKI after PCI was 9\% [2]. In PCI patients with AKI, the length of hospital stay was prolonged, the survival rate decreased, and the incidence of cardiovascular events and end-stage renal diseases also increased [3]. It has been reported that even

Ya-feng Zhang and Da-dong Liu contributed equally to this work. 


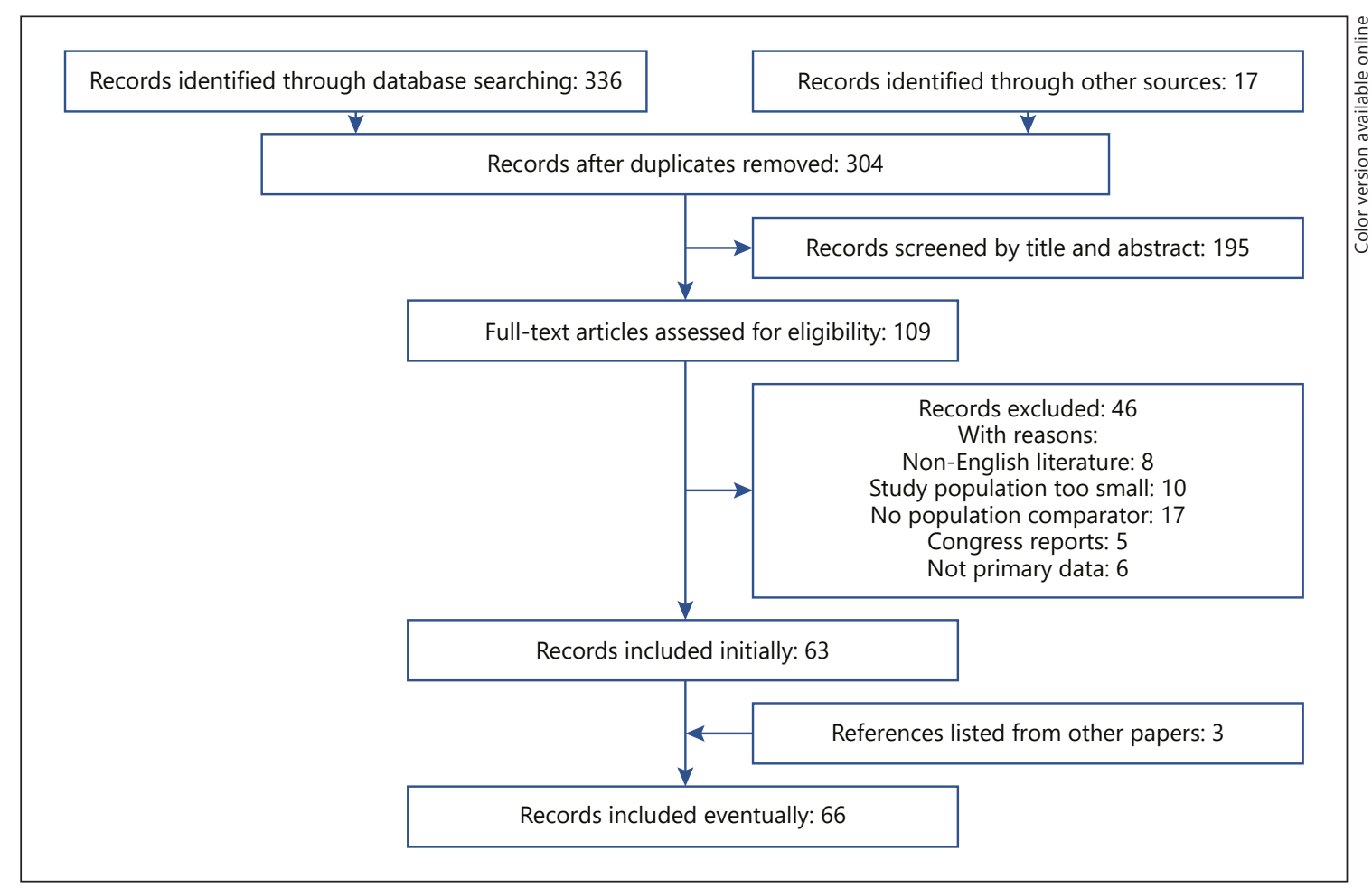

Fig. 1. The flowchart of the literature selection process.

mild deterioration of renal function after PCI that does not meet the criteria for AKI was associated with increased long-term mortality [4].

Therefore, early prevention, identification, and intervention of AKI after PCI are of great importance. With the keywords of "acute kidney injury," " percutaneous coronary intervention," and "acute coronary syndrome," we searched SinoMed, Web of Science, and PubMed databases for articles in recent years (Fig. 1), and reviewed the etiologies and pathogenesis, influencing factors and preventive measures of AKI in patients with ACS after PCI, in order to provide reference for clinical research.

\section{Definition and Diagnostic Criteria of AKI}

AKI after PCI is easy to be ignored for it is often accompanied by other complications such as cardiac dysfunction which themselves can lead to deterioration of the condition. Different terminologies and diagnostic criteria have been used historically for AKI, so there were significant differences in the evaluation of AKI after PCI. Many studies have been carried out for the definition and standard of AKI in the past few years. In 2004, Acute Di- alysis Quality Initiative (ADQI) group used risk-injuryfailure-loss-end-stage kidney disease (RIFLE) classification as a consensus definition for early detection and grading of AKI. According to this standard, AKI is divided into 3 phases (i.e., risk, injury, and failure) according to changes in serum creatinine ( $\mathrm{Scr}$ ) and urine output [5]. The Acute Kidney Injury Network (AKIN) composed of nephrologists and intensive care specialists proposed a modification of the RIFLE classification subsequently [6]: (1) The change in the absolute value of Scr was added, the range of "risk of acute kidney injury" was expanded to Scr, increased $\geq 26.5 \mu \mathrm{mol} / \mathrm{L}$, and classified as AKI stage 1 (corresponding to RIFLE risk stage); (2) $48 \mathrm{~h}$ were taken as the time limit to ensure that AKI process is a representative event occurring within a relatively short period of time; (3) patients who received renal replacement therapy were considered to meet the criteria for stage 3 (corresponding to RIFLE failure stage). The definition of AKI was further refined in 2012 by the Kidney Disease Improving Global Outcomes Organization (KDIGO) [7]: increase in $\mathrm{Scr} \geq 0.3 \mathrm{mg} / \mathrm{dL}(26.5 \mu \mathrm{mol} / \mathrm{L})$ within $48 \mathrm{~h}$, or increase in $\mathrm{Scr} \geq 1.5$ times baseline in 7 days, or urine volume $<0.5 \mathrm{~mL} / \mathrm{kg} / \mathrm{h}$ for $6 \mathrm{~h}$. The staging criteria are shown in Table 1. 
Table 1. RIFLE, AKIN, and KDIGO classifications for AKI

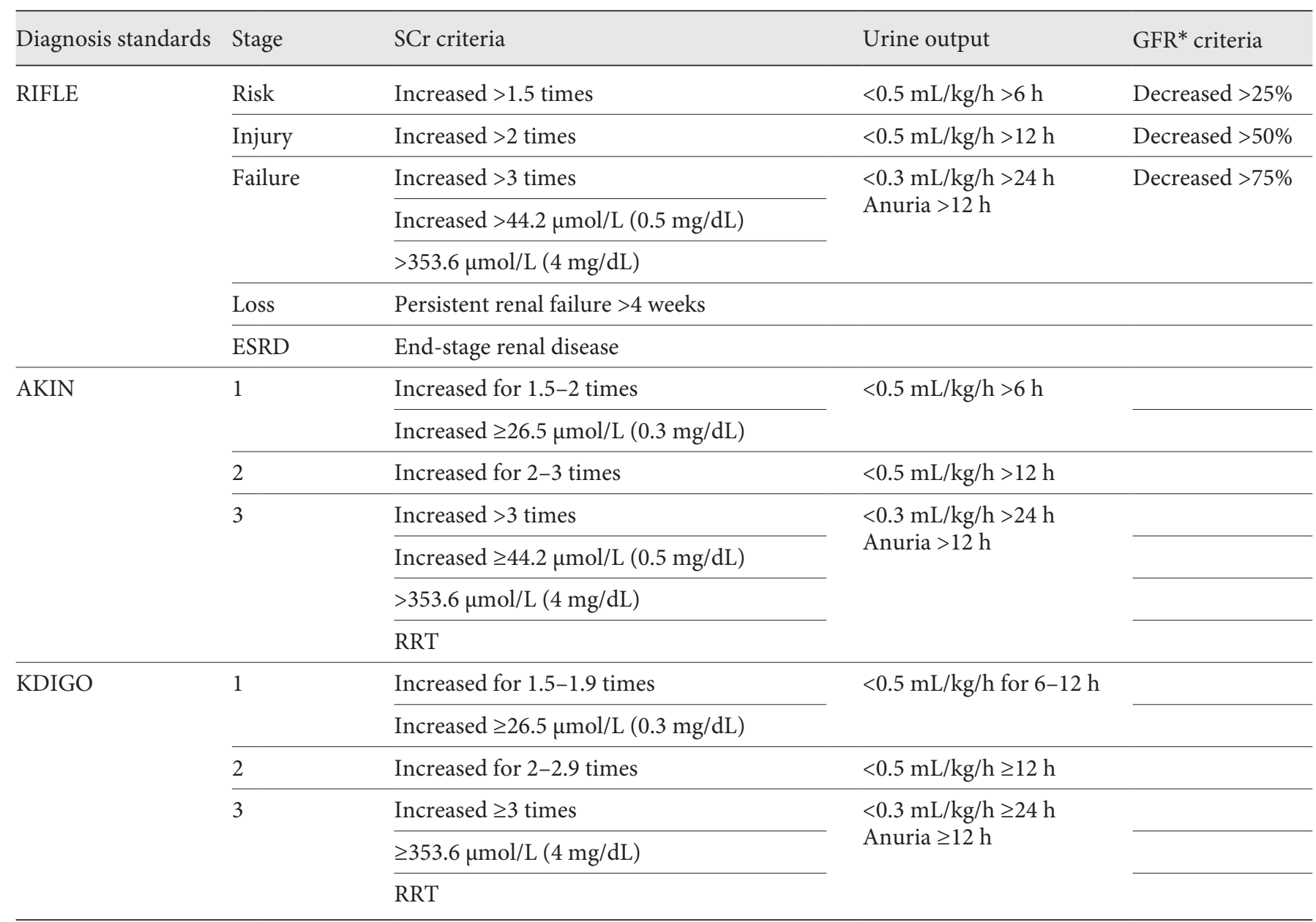

* GFR, glomerular filtration rate; AKI, acute kidney injury; Scr, serum creatinine; ESRD, end-stage renal disease; RRT, renal replacement therapy; KDIGO, Kidney Disease Improving Global Outcomes Organization; AKIN, Acute Kidney Injury Network; RIFLE, risk-injury-failure-loss-end-stage kidney disease.

\section{Etiologies and Pathogenesis}

The pathophysiological features of AKI after PCI are complex and multifactorial, including renal damage of contrast medium and atherosclerotic embolism, cardiac insufficiency, and surgical factors on renal function. These mechanisms of injury are interrelated and likely to be active with different intensities at different times (shown in Fig. 2).

\section{Renal Damage of Contrast Medium}

Studies have shown that one of the important causes for AKI after PCI is the nephrotoxicity of iodine contrast agents [3]. It is reported that the incidence of contrast agent-induced AKI is as high as $10-30 \%$, which has be- come the third major inducement of iatrogenic AKI [8]. The pathogenesis of contrast-induced nephropathy (CIN) is complex and has not been fully elucidated. The main mechanisms known include direct damage of contrast media $(\mathrm{CM})$ to renal tubular epithelial cells, ischemia and hypoxia of renal medulla, injury of oxygen free radicals, inflammatory response, etc. [9]. Contrast media can decrease the activity of renal tubular epithelial cells by activating a series of ion channels, and activate a variety of apoptosis pathways to induce apoptosis of renal tubular epithelial cells [10]; the use of CM causes the transient increase and then the continuous decrease of renal blood flow, resulting in insufficient medullary perfusion. The osmotic diuretic effect of contrast agents leads to the decrease of blood circulation and the aggravation of renal 


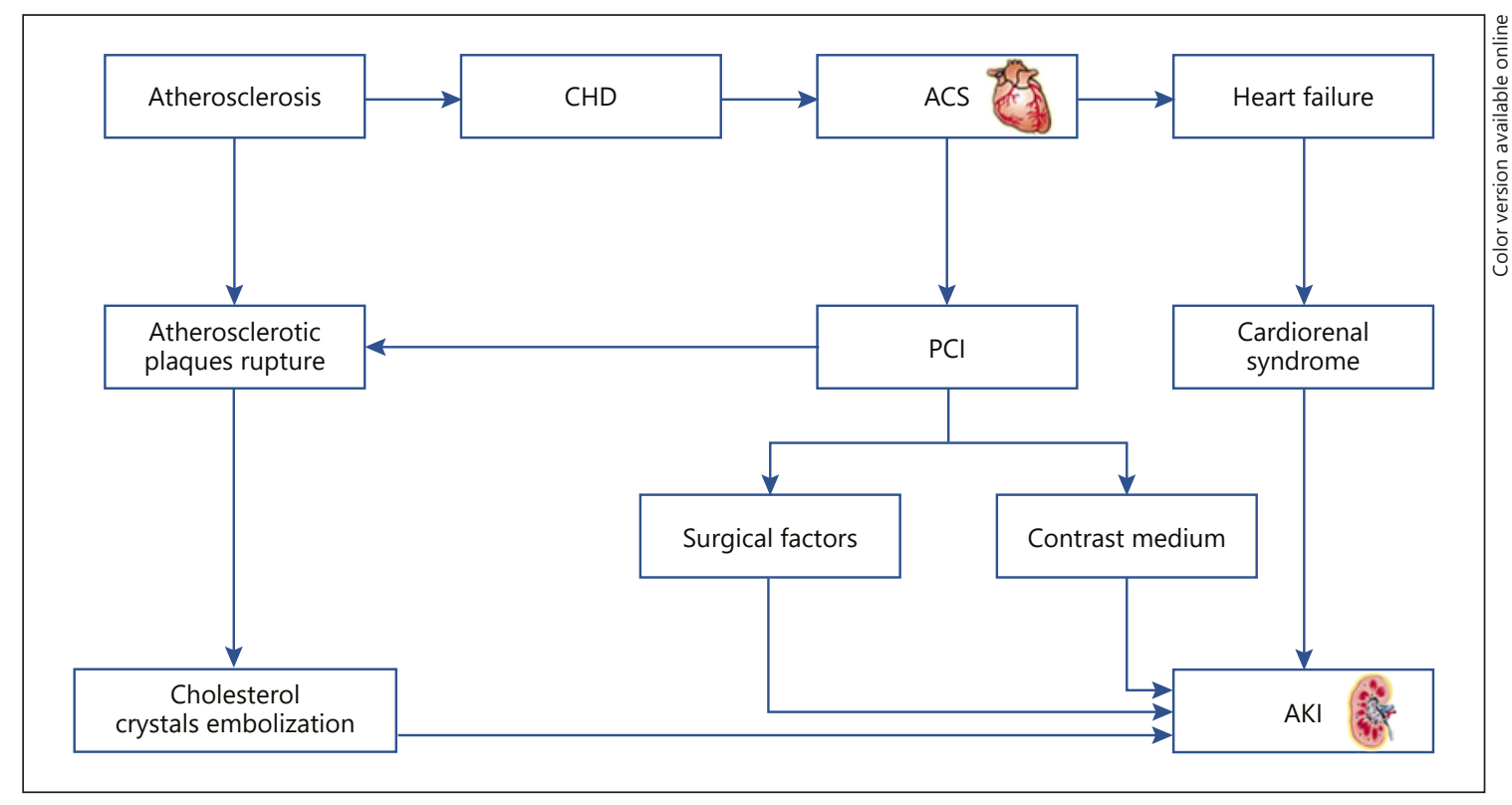

Fig. 2. The pathophysiological features of AKI after PCI. AKI, acute kidney injury; PCI, percutaneous coronary intervention; ACS, acute coronary syndrome; $\mathrm{CHD}$, coronary heart disease.

ischemia. Contrast agents may increase the pressure and liquid viscosity in renal tubules, and then lead to high quantity oxygen consumption of renal tubules. Contrast medium aggravates the ischemia and hypoxia of medulla by renal vasoconstriction on account of reducing the production of nitric oxide (NO) [11].

\section{Cardiac Insufficiency on Renal Function}

The cardiac function may deteriorate in a short period of time during the onset of ACS, manifesting as decompensated heart failure. The process of kidney injury caused by heart failure after ACS is consistent with the manifestations of type I cardiorenal syndrome. The incidence of renal dysfunction in patients with acute heart failure (AHI) and chronic heart failure was 23\% and 25\%, respectively [12]. This indicates that cardiac insufficiency plays an important role in promoting the deterioration of renal function. The mechanism of AKI caused by cardiac insufficiency includes hemodynamic and nonhemodynamic factors. The main hemodynamic mechanism is that the decrease of cardiac output caused by ACS leads to the insufficiency of renal artery perfusion, the increase of renal vein pressure and the decrease of glomerular filtration rate (GFR), and eventually causes kidney injury [13]. At the same time, affected by hemodynamic changes, neurohumoral feedback systems, such as sympathetic nervous system and renin angiotensin aldosterone sys- tem (RAAS) are overactivated, which can cause vasoconstriction and further kidney injury [14]. Other studies have shown that ACS patients usually suffer from defects in the regulation of apoptosis and inflammatory pathway activation during the onset of the disease, and the overactivation of monocytes and the direct effect of pro-inflammatory factors can also cause renal tissue injury [15]. The above 2 constitute nonhemodynamic factors.

\section{Atherosclerotic Embolic Renal Injury}

ACS patients suffer from obvious atherosclerosis. Cholesterol crystals in the plaques released into blood circulation may lead to embolism of multiple arterioles (including renal arterioles) when atherosclerotic plaques rupture [16]. In the meantime, Platelets are activated by substances released from the vascular wall cells and secrete pro-inflammatory chemokines and cytokines, which participate in vascular inflammation, thus aggravating the disease [17]. Based on the analysis of a large number of clinical literature, Quinones and others found that more than $70 \%$ of atherosclerotic plaque rupture events are caused by iatrogenic operation (especially arteriography), and the use of anticoagulants in the perioperative period can interfere with the healing of atherosclerotic plaque ulcers, further increase the release of cholesterol crystals [18]. Cholesterol crystals embolization can cause damage to renal function in a short period of time 
when multiple tiny blood vessels of kidney are involved. The pathogenesis includes cholesterol embolism and inflammatory reaction. Cholesterol crystals flow to the distal vessels with bloodstream, blocking renal arterioles and causing multiple renal micro embolisms. Cholesterol crystals often lead to incomplete blockage of renal arterioles due to the irregular shapes and nondeformed features. Secondary acute inflammation fills the blood vessels with multinucleated neutrophils and eosinophils. Subsequent foreign-body reactions cause the result that monocytes appear in the blood vessels, which later turn into megakaryocytes and then phagocytize cholesterol crystals. At the same time, thrombosis occurs in the micro vasculars follow with angiointimal hyperplasia, and subsequently develop into vascular fibrosis, which eventually result in complete occlusion of the vascular lumens [19].

\section{Surgical Factors on Renal Function}

A large number of inflammatory factors, such as tumor necrosis factor $\alpha$ and interleukin- 6 or interleukin-8, etc., are released into blood by the stress reaction caused by operation, which can directly cause lipid peroxidation of renal tubular epithelial cell membrane, necrosis and abscission of renal tubular epithelial cells, and damage of renal tubular basement membrane. The above lesions may involve all segments of renal tubules [20], cause the decline of renal reabsorption function, then lead to a decrease of water and sodium retention capacity of kidneys, so the circulation blood volume is reduced and decreased renal perfusion blood volume further aggravates kidney injury. Postoperative complications, such as spasm, embolism, and endothelial injury of coronary arteries may lead to circulatory dysfunction, resulting in hypovolemia and acute prerenal damage. Postoperative platelet activation could further aggregate neutrophils and fibrin, promote micro thrombosis in the glomerulus, causing nephron damage and eventually the decline of renal function [21]. It has been reported that postoperative coagulation dysfunction causes glomerular hemorrhage, while the destruction of glomerular filtration barrier leads to hemorrhage in Bowman's capsule and renal tubule, and finally results in obstruction of renal tubule lumen [22].

\section{Risk Factors}

Underlying Conditions of Patients

Basic Diseases

Patients of AKI after PCI have a high prevalence of basic diseases, such as hypertension and diabetes. Hyper- tension can cause contraction and sclerosis of renal arterioles, resulting in renal perfusion insufficiency and renal ischemia. Diabetic patients often suffer from systemic multivascular diseases, and renal atherosclerosis and glomerulosclerosis are high-risk factors for AKI. Hyperuricemia was also reported independent risk factor of CIN after PCI [23]. Hyperuricemia can inhibit NO system, enhance inflammatory response, and participate in a variety of atherosclerotic processes, including oxidative stress, vascular smooth muscle cell proliferation, RAAS activation, and endothelial dysfunction [24]. In addition, decreased oxygen carrying capacity of blood may cause renal damage by aggravating ischemia and hypoxia of the renal medulla in anemia patients [25].

\section{Baseline Renal Function}

GFR decreases by about $1 \mathrm{~mL} / \mathrm{min}$ per year in patients over 40 years of age [26], so elderly patients have poor baseline renal function. Patients with chronic kidney disease (CKD) are prone to renal damage on account of impaired basic renal function, slow filtration of $\mathrm{CM}$, and weak endurance to renal hypoperfusion caused by hemodynamics changes during and after PCI. A retrospective study of 406 patients with acute myocardial infarction undergoing PCI showed that age was one of the independent risk factors for AKI [27]. Another study reported that the incidence of AKI after PCI in CKD patients was 2.6 times that in non-CKD patients (8.4\% vs. 3.2\%) [28]. Therefore, the basic renal function of patients has important influence on the occurrence of AKI after PCI.

\section{Treatment Modalities}

Number of Operations

Repeated operation is the high-risk factor of AKI. On the one hand, patients who need reoperation often suffer from severe coronary lesions, which is a typical symptom of systemic arteriosclerosis. Such patients are prone to postoperative renal damage due to endothelial dysfunction and diastolic dysfunction of renal vessels [3]. On the other hand, repeated use of CM and stress response to PCI is also risk factors for kidney injury.

Types and Dosage of Contrast Media

It is generally believed that high-osmolar CM is more likely to cause CIN than that of iso-osmolar or low-osmolar CM. Luk et al. [29] reported that the risk of renal damage caused by high-osmolar CM is 3.3 times than that of low-osmolar CM. While an in vitro study showed that the oxidative stress and DNA damage of renal HK-2 cells induced by isotonic CM were greater than those by 
low permeability CM [30]. Another research suggested that the viscosity of $\mathrm{CM}$ was more significant in predicting the incidence rate of CIN for having a greater effect on renal medulla ischemia than osmotic pressure [31]. Ionic CM is more likely to cause microvascular obstruction and impair renal function than nonionic $\mathrm{CM}$ for its higher viscosity. The dosage of contrast medium is also related to the occurrence of CIN. A study of 2,308 patients undergoing PCI showed that the risk of CIN significantly increased when the ratio of the dosage of $\mathrm{CM}$ $(\mathrm{mL})$ to the creatinine clearance rate $(\mathrm{mL} / \mathrm{min})$ was $>6.15$ [32].

\section{Perioperative Medications}

Massive dose of vasoactive drugs in perioperative period may cause significant reduction of circulatory blood volume and contraction of renal vessels, further induce the decline of renal blood flow and accordingly the decrease of GFR, and then the aggravation of renal ischemia leads to the necrosis of renal tubular epithelial cells and damage of renal function [33]. Abuse of loop diuretics can cause activation of sympathetic nervous system and RAAS, resulting in increased peripheral vascular resistance, decreased left ventricular ejection fraction and renal perfusion, and ultimately AKI [34]. Excessive anticoagulants not only directly damage the glomerulus, but also cause acute renal damage due to red blood cells blocking renal tubules after glomerular hemorrhage, and also renal damage through oxidative stress, arterial embolism, interstitial nephritis, apoptosis of glomerular endothelial cells, and other ways [35]. Besides, AKI can also be caused by inappropriate antihypertensive programs, such as the decrease of renal perfusion due to excessive depressurization, or the use of RAAS inhibitors in patients with bilateral renal artery stenosis.

\section{Postoperative Infection}

Postoperative infection is an important factor of renal injury. Patients undergoing PCI are prone to infection due to low immune function and postoperative stress. A retrospective survey of 903 patients undergoing PCI in Italy revealed that the infection rate of major sites (including respiratory, circulatory, and digestive systems) within 60 days after PCI was about 2.5\% [36]. The pathogenesis of AKI caused by infection is complicated and has not been fully elucidated. Most scholars believe that systemic vasodilation and renal vasoconstriction lead to decreased renal blood flow and renal hypoperfusion during severe infection [37].

Reviewing the Etiologies, Influencing

Factors, and Preventive Measures

\section{Preventive Measures}

Key studies illustrating the preventive measures of AKI after PCI are outlined in Table 2. The discussion on various preventive measures is presented below.

\section{Prevention of CIN}

Personalized Hydration

Hydration therapy is the most economical and effective means to prevent CIN after PCI [38]. At present, the mechanism of hydration is considered to increase blood volume and renal perfusion, to reduce the permeability and diuretic effect of $\mathrm{CM}$, to inhibit the activation of RAAS, and to raise the concentration of vasodilators, such as NO. At the same time, hydration can reduce the concentration of CM in renal tubules, so as to ameliorate the direct damage of CM to renal tubule epithelial cells [39]. Hydration can be administered orally or intravenously, both of which have been reported to be effective in preventing CIN [40]. However, intravenous hydration is more clinically acceptable than the oral one due to its quantifiable operability. Many researches have been carried out to explore the reasonable volume of rehydration. A prospective study that included 711 emergency PCI patients for prophylactic hydration showed that high hydration vol/wt ratio did neither reduce the incidence of CIN nor improve long-term prognosis [41]. At present, it is presumed that in the case of high-risk patients without any indications of heart failure, saline should be administered $6-12 \mathrm{~h}$ before the contrast exam at $1 \mathrm{~mL} / \mathrm{kg} / \mathrm{h}$ and continue for additional $12-24 \mathrm{~h}$ after the contrast examination [42].

Alkalization

Alkalization therapy has been shown to reduce the incidence of CIN by increasing the concentration of sodium bicarbonate in renal tubules, inhibiting the acidification of renal tubules and medulla, neutralizing oxygen free radicals, and ultimately protecting renal function [43]. It was found that sodium citrate and sodium bicarbonate could both effectively reduce the morbidity of CIN in coronary angiography and PCI patients [44], while hydration with sodium bicarbonate reduced contrast-induced renal impairment more effectively than hydration with saline [45]. Other studies showed that sodium bicarbonate alkalization had no advantage over isotonic saline in the prevention of CIN [46]. A metaanalysis found that sodium bicarbonate had an ideal effect on the prevention of renal damage caused by emergency coronary angiography, and the preventive effect of 
Table 2. Preventive measures of AKI in patients after PCI

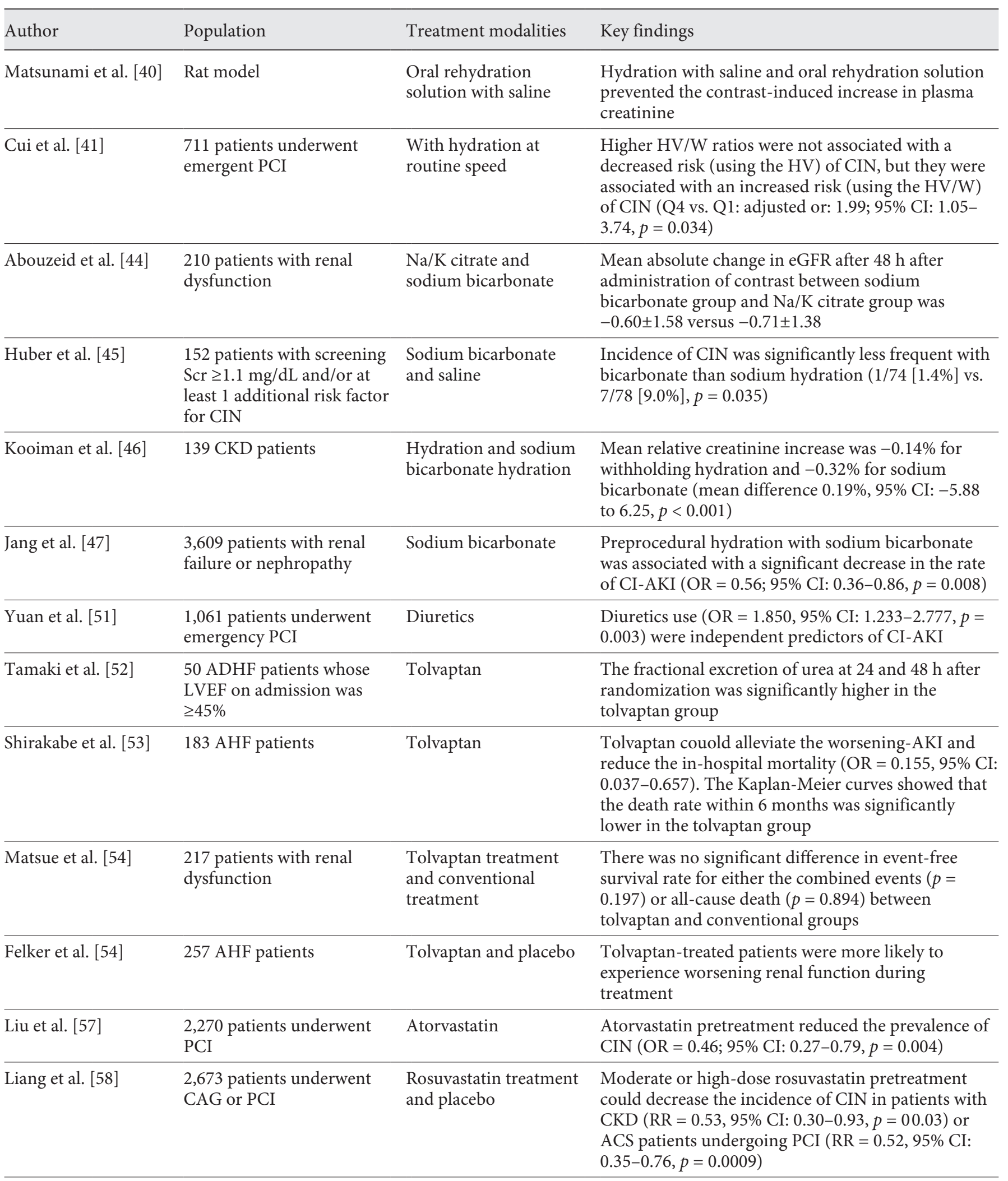


Table 2 (continued)

\begin{tabular}{|c|c|c|c|}
\hline Author & Population & Treatment modalities & Key findings \\
\hline Wang et al. [59] & Rat model of CI-AKI & Different statins & $\begin{array}{l}\text { Simvastatin cannot ameliorat CM-induced Scr } \\
\text { elevation and histopathological alterations }\end{array}$ \\
\hline Garcia et al. [62] & 5,177 patients with CKD & $\begin{array}{l}\text { Oral acetylcysteine and } \\
\text { placebo }\end{array}$ & $\begin{array}{l}23 \text { of } 598 \text { patients }(3.8 \%) \text { in the acetylcysteine group } \\
\text { and } 16 \text { of } 563 \text { patients }(2.8 \%) \text { in the placebo group } \\
(\mathrm{OR}=1.37,95 \% \mathrm{CI}: 0.71-2.62, p=0.29)\end{array}$ \\
\hline Erturk et al. [64] & $\begin{array}{l}307 \text { patients with eGFR of } \\
<60 \mathrm{~mL} / \mathrm{min} / 1.73 \mathrm{~m}^{2}\end{array}$ & i.v. and oral NAC & $\begin{array}{l}6.8 \% \text { in the saline group, } 13.7 \% \text { in the oral NAC } \\
\text { group, and } 12.7 \% \text { in the i.v. NAC group }(p=0.231) \text {. } \\
\text { That of cystatin C-based CIN was } 8.1 \%: 6.8 \% \text { in the } \\
\text { saline group, } 6.9 \% \text { in the oral NAC group, and } 10.8 \% \\
\text { in the i.v. NAC group }(p=0.491)\end{array}$ \\
\hline Liang et al. [67] & 480 patients with CHD & Alprostadil & $\begin{array}{l}\text { Alprostadil was the protective factor of CIN (OR = } \\
0.699,95 \% \text { CI: } 0.542-0.902, p=0.006)\end{array}$ \\
\hline Sav et al. [69] & $\begin{array}{l}77 \text { patients with cardiorenal } \\
\text { syndrome }\end{array}$ & $\begin{array}{l}\text { Ultrafiltration and } \\
\text { furosemide treatment }\end{array}$ & $\begin{array}{l}\text { Plasma SOD, CAT, MDA, and GSH-Px levels did not } \\
\text { show significant difference between the groups }\end{array}$ \\
\hline \multicolumn{4}{|c|}{$\begin{array}{l}\text { ACS, acute coronary syndrome; ADHF, acute decompensated heart failure; AHF, acute heart failure; CAG, coronary angiography; } \\
\text { CAT, catalase; CI-AKI, contrast-induced acute kidney injury; CIN, contrast-induced nephropathy; CKDs, chronic kidney diseases; CM, } \\
\text { contrast media; GSH-Px, glutathione peroxidase; HV/W, HV or HV to weight; LVEF, left ventricular ejection fraction; MDA, } \\
\text { malondialdehyde; NAC, N-acetylcysteine; PCI, percutaneous coronary intervention; SOD, superoxide dismutase; CHD, coronary heart } \\
\text { disease; Scr, serum creatinine; eGFR, estimated glomerular filtration rate; i.v., intravenous. }\end{array}$} \\
\hline
\end{tabular}

CIN caused by low-osmolar CM was better than that of iso-osmolar CM [47]. It is speculated that hydration and alkalization have different preventive effects on patients with different underlying conditions, and further study on the indications of both is necessary to play a greater role in renal protection.

\section{Modulating Volume Overload}

Diuretics

Diuretics have been used as the first-line agents for the treatment of heart failure, which can reduce cardiac preload and afterload and play a role in renal protective effect on ACS patients with cardiorenal syndrome. Loop diuretics can inhibit $\mathrm{Na}^{+}-\mathrm{K}^{+}-\mathrm{Cl}^{-}$pump on lumen membrane of the medullary loop, reduce oxygen demand of renal medullary, and thereby reduce the damage of kidney. Moreover, increased urine volume can further assist in the regulation of body fluid, $\mathrm{pH}$, and electrolyte [48]. Compared with furosemide, torasemide has a better effect on alleviating renal damage due to the additional effect on antagonizing aldosterone, which can inhibit the activation of RAAS [49]. Torasemide can also reduce the activity of prostaglandin-degrading enzyme in renal cortex and medulla, increase the level of prostaglandin and prostacyclin in plasma, and thereby improve renal microcirculation [50]. However, the use of diuretics is still controversial. A retrospective study involving 1,061 patients revealed that the use of diuretics may increase the risk of CIN after PCI, possibly because of the effect of decreasing renal blood flow and elevating the concentration of CM in blood [51]. Therefore, the timing and dosage of diuretics should be controlled in clinical application to avoid the aggravation of renal damage caused by insufficient effective volume. 
Selective Vasopressin Receptor Antagonist

Tolvaptan is a type of vasopressin V2 receptor antagonist and widely studied in recent years, which can exert diuretic effect without promoting electrolyte excretion. Because patients with ACS complicated by heart failure are prone to diuretic resistance, increasing the dosage of diuretics is not only ineffective but also at risk of aggravating renal damage, While tolvaptan can work by its effect on renal collecting duct and then relieve the volume overload, avoiding the disadvantage of loop diuretics. A prospective study showed that tolvaptan could reduce the volume overload and the risk of renal injury in patients with heart failure accompanied by diuretic resistance [52]. Another study also reported that tolvaptan can increase renal blood flow, prevent the deterioration of AKI, and improve the prognosis of patients with AHI [53]. However, Matsue et al. [54] reported that the prognosis of patients with $\mathrm{AHI}$ and renal insufficiency was not significantly improved by short-term use of tolvaptan, and another tactics-hf study showed that the use of tolvaptan within $24 \mathrm{~h}$ of AHI presentation can greatly alleviate the symptoms of volume overload, but tolvaptan-treated patients were more likely to experience worsening renal function during treatment [55]. Therefore, more authoritative evidence-based medicine is needed to confirm the exact effect of tolvaptan on renal function in relieving heart failure.

\section{Other Pharmaceuticals}

Statins

Statins may protect renal function and decrease the morbidity of AKI after PCI by promoting the expression of heat-shock protein 90 , increasing the production of $\mathrm{NO}$ and improving the function of vascular endothelial cells [56]. A meta-analysis study reported that atorvastatin pretreatment was associated with a significant reduction in the prevalence of contrast-induced AKI in patients undergoing PCI [57]. Another research reported that preoperative-enhanced treatment of rosuvastatin $(20 \mathrm{mg} /$ days $)$ could also effectively reduce the incidence of postoperative AKI [58]. An animal experiment indicated that renal protective effects of different statins are various, and simvastatin is relatively less effective in relieving inflammation and oxidative stress [59]. In recent studies, it is still controversial whether statins reduce the mortality of AKI, mainly due to the insufficient samples, disunited dosage and application of medicine, and the different clinical characteristics of research subjects [60].

\section{Antioxidant}

Previous animal experiment suggested that $\mathrm{N}$-acetylcysteine could scavenge oxygen free radicals, ameliorate postoperative oxidative stress, and reduce the renal toxicity of CM. In addition, it can increase the production of $\mathrm{NO}$, and thus dilate renal vessels and increase renal blood flow. Therefore, $\mathrm{N}$-acetylcysteine can theoretically prevent renal damage after PCI [61]. While its efficacy is still controversial in current clinical studies, a large-scale randomized trial found that among patients with CKD are at high risk for renal complications undergoing PCI, there was no benefit of oral acetylcysteine over placebo for the prevention of AKI $[62,63]$. A study of 307 patients showed that neither oral nor intravenous $\mathrm{N}$-acetylcysteine had significant advantage on acute renal damage in patients with primary kidney disease after PCI [64]. Some scholars believe that trimetazidine can play a role in renal protection by eliminating oxygen free radicals, improving oxidative stress, and inhibiting the accumulation of toxic substances [65]. But the current clinical trials are mostly single-center researches with small sample size. Therefore, further studies should be implemented to explore the renal protective effect of antioxidants after PCI.

\section{Alprostadil}

Alprostadil (prostaglandin E1) can protect renal function by dilating renal vessels, increasing renal blood flow, inhibiting platelets and erythrocytes aggregation, reducing blood viscosity, restoring the synthesis of basement membrane proteins, and inhibiting the production of inflammatory mediators, and infiltration of inflammatory cells [66]. It has been reported that prophylactic use of alprostadil in the perioperative period can effectively prevent $\mathrm{AKI}$ in PCI patients [67]. However, the preventive effect of alprostadil is related to the dosage, mode, and timing of administration that need to be further studied.

\section{Blood Purification}

Patients with ACS associated with cardiorenal syndrome often suffer from hemodynamic instability. The use of blood purification and ultrafiltration in patients with poor efficacy of drugs can remove excess water and inflammatory mediators, ameliorate myocardial preload, improve myocardial contractility, thus increase renal perfusion and play a role in protecting renal function [68]. Short-term use of both blood ultrafiltration treatment and furosemide treatment can effectively reduce circulatory overload, ameliorate oxidative stress, and improve renal function in patients with cardiorenal syndrome [69]. While for refractory cardionrenal syndrome, ultra- 
filtration may provoke less neurohormonal activation than diuretic therapy, which leads to greater sustainability of beneficial effects [70]. In addition, some literatures reported that continuous hemodiafiltration could remove the medium molecular and macromolecular CM in patients by using high permeability and high biocompatibility filter, and had more advantages than conventional hydration in the prevention of CIN on account of being implemented by means of liquid ultrafiltration at the same time of replacement liquid supplement and not prone to cause volume overload [8]. Nevertheless, due to the high cost and corresponding risks (such as infection, bleeding, embolism, etc.), blood purification is not recommended as the preferred option to prevent AKI after PCI.

\section{Conclusion}

It is the common responsibility of cardiologists and nephrologists to pay attention to renal injury during the diagnosis and treatment of ACS. Researches on the pathophysiologies and risk factors of AKI after PCI have been continuously developed, but there are currently no specific effective preventive measures for AKI, and it is still necessary to follow-up cases with large samples from multiple centers to seek more accurate basis. Reasonable prevention programs, such as the risk factors of AKI being avoided as early as possible, the preoperative basic status of patients being adequately evaluated, the primary diseases being actively treated, and renal damage being early detected and controlled may reduce the morbidity of AKI and improve the prognosis of patients.

\section{Conflict of Interest Statement}

The authors have no conflicts of interest to declare.

\section{Funding Sources}

The authors did not receive any funding.

\section{Author Contributions}

Ya-feng Zhang and Da-dong Liu worked on literature retrieval and analysis. Yue Zhou and Ji-zhuang Lou worked on research design and thesis writing. All authors reviewed and edited the final draft.

\section{References}

1 World Health Organization. Global status report on noncommunicable diseases. 2010. [EB/OL]. Available from: http://www.who int/nmh/publications/ncd_report2010/en/ (2011). Accessed 2017 Nov 2.

2 Karrowni W, Vora AN, Dai D, Wojdyla D, Dakik H, Rao SV. Blood transfusion and the risk of acute kidney injury among patients with acute coronary syndrome undergoing percutaneous coronary intervention. Circ Cardiovasc Interv. 2016 Sep;9(9):e003279.

3 Brown JR, Rezaee ME, Nichols EL, Marshall EJ, Siew ED, Matheny ME, et al. Incidence and in-hospital mortality of acute kidney injury (AKI) and dialysis-requiring AKI (AKID) after cardiac catheterization in the national inpatient sample. J Am Heart Assoc. 2016 Mar;5(3):e002739.

4 Kanic V, Suran D, Vollrath M, Tapajner A, Kompara G. Influence of minor deterioration of renal function after PCI on outcome in patients with ST-elevation myocardial infarction. J Interv Cardiol. 2017 Oct;30(5):473-9.

5 Bellomo R, Ronco C, Kellum JA, Mehta RL, Palevsky P; ADQI workgroup. Acute renal failure-definition, outcome measures, animal models, fluid therapy and information technology needs: the Second International Consensus Conference of the Acute Dialysis
Quality Initiative (ADQI) Group. Crit Care. 2004 Aug;8(4):R204-12.

6 Mehta RL, Kellum JA, Shah SV, Molitoris BA, Ronco C, Warnock DG, et al. Acute kidney injury network: report of an initiative to improve outcomes in acute kidney injury. Crit Care. 2007;11(2):R31.

7 Kidney Disease: Improving Global Outcomes (KDIGO) Acute Kidney Injury Work Group. KDIGO clinical practice guideline for acute kidney injury. Kidney Int Suppl. 2012;2:1138.

8 Mohammed NM, Mahfouz A, Achkar K, Rafie IM, Hajar R. Contrast-induced Nephropathy. Heart Views. 2013 Jul;14(3):10616.

9 Ozkok S, Ozkok A. Contrast-induced acute kidney injury: a review of practical points. World J Nephrol. 2017 May;6(3):86-99.

10 Andreucci M, Faga T, Russo D, Bertucci B, Tamburrini O, Pisani A, et al. Differential activation of signaling pathways by low-osmolar and iso-osmolar radiocontrast agents in human renal tubular cells. J Cell Biochem. 2014 Feb;115(2):281-9.

11 Liu ZZ, Schmerbach K, Lu Y, Perlewitz A, Nikitina $\mathrm{T}$, Cantow $\mathrm{K}$, et al. Iodinated contrast media cause direct tubular cell damage, leading to oxidative stress, low nitric oxide, and impairment of tubuloglomerular feedback. Am J Physiol Renal Physiol. 2014 Apr;306(8): F864-72.

12 Damman K, Valente MA, Voors AA, O'Connor CM, Van Veldhuisen DJ, Hillege $\mathrm{HL}$, et al. Renal impairment, worsening renal function, and outcome in patients with heart failure: an updated meta-analysis. Eur Heart J. 12014 Feb;35(7):455-69.

13 Di Lullo L, Bellasi A, Barbera V, Russo D, Russo L, Di Iorio B, et al. Pathophysiology of the cardio-renal syndromes types 1-5: an update. Indian Heart J. 2017 MarApr;69(2): 255-65.

14 Matsushita K. Pathogenetic pathways of cardiorenal syndrome and their possible therapeutic implications. Curr Pharm Des. 2016; 22(30):4629-37.

15 Colombo PC, Ganda A, Lin J, Onat D, Harxhi $A$, Iyasere JE, et al. Inflammatory activation: cardiac, renal, and cardio-renal interactions in patients with the cardiorenal syndrome. Heart Fail Rev. 2012 Mar;17(2):177-90.

16 Li X, Bayliss G, Zhuang S. Cholesterol crystal embolism and chronic kidney disease. Int J Mol Sci. 2017 May;18(6):1120.

17 Kurtul A, Ornek E. Platelet to lymphocyte ratio in cardiovascular diseases: a systematic review. Angiology. 2019 Oct;70(9):802-18.
Reviewing the Etiologies, Influencing Factors, and Preventive Measures 
18 Quinones A, Saric M. The cholesterol emboli syndrome in atherosclerosis. Curr Atheroscler Rep. 2013 Apr;15(4):315.

19 Ghanem F, Vodnala D, Kalavakunta JK, Durga S, Thormeier N, Subramaniyam P, et al. Cholesterol crystal embolization following plaque rupture: a systemic disease with unusual features. J Biomed Res. 2017 Jan;31(2): 82-94.

20 Vives M, Wijeysundera D, Marczin N, Monedero P, Rao V. Cardiac surgery-associated acute kidney injury. Interact Cardiovasc Thorac Surg. 2014 May; 18(5):637-45.

21 Raso Vasquez AO, Kertai MD, Fontes ML. Postoperative thrombocytopenia: why you should consider antiplatelet therapy? Curr Opin Anaesthesiol. 2018 Feb;31(1):61-6.

22 Wheeler DS, Giugliano RP, Rangaswami J. Anticoagulation-related nephropathy. J Thromb Haemost. 2016 Mar;14(3):461-7.

23 Barbieri L, Verdoia M, Schaffer A, Cassetti E, Marino P, Suryapranata H, et al. Uric acid levels and the risk of contrast induced nephropathy in patients undergoing coronary angiography or PCI. Nutr Metab Cardiovasc Dis. 2015 Feb;25(2):181-6.

24 Filiopouous V, Hadjiyannakos D, Vlassopoulos D. New insights into uric acid effects on the progression and prognosis of chronic kidney disease. Ren Fail. 2012; 34(4):510-20.

25 Murakami R, Kumita S, Hayashi H, Sugizaki K, Okazaki E, Kiriyama T, et al. Anemia and the risk of contrast-induced nephropathy in patients with renal insufficiency undergoing contrast-enhanced MDCT. Eur J Radiol. 2013 Oct;82(10):e521-4.

26 Stevens LA, Coresh J, Greene T, Levey AS. Assessing kidney function: measured and estimated glomerular filtration rate. $\mathrm{N}$ Engl J Med. 2006 Jun;354(23):2473-83.

27 Queiroz RE, de Oliveira LS, de Albuquerque CA, Santana Cde A, Brasil PM, Carneiro LL, et al. Acute kidney injury risk in patients with ST-segment elevation myocardial infarction at presentation to the ED. Am J Emerg Med. 2012 Nov;30(9):1921-7.

28 Kuźma Ł, Małyszko J, Kurasz A, Niwińska MM, Zalewska-Adamiec M, BachórzewskaGajewska $\mathrm{H}$, et al. Impact of renal function on patients with acute coronary syndromes: 15,593 patient-years study. Ren Fail. 2020 Nov;42(1):881-9.

29 Luk L, Steinman J, Newhouse JH. Intravenous contrast-induced nephropathy-the rise and fall of a threatening idea. Adv Chronic Kidney Dis. 2017 May;24(3):169-75.

30 Ludwig U, Connemann J, Keller F. Effect of low-osmolar contrast medium iopromide and iso-osmolar iodixanol on DNA fragmentation in renal tubular cell culture. Clin Exp Nephrol. 2013 Dec;17(6):779-82.

31 Bucher AM, De Cecco CN, Schoepf UJ, Meinel FG, Krazinski AW, Spearman JV, et al. Is contrast medium osmolality a causal factor for contrast-induced nephropathy? Biomed Res Int. 2014;2014:931413.
32 Barbieri L, Verdoia M, Marino P, Suryapranata H, De Luca G; Novara Atherosclerosis Study Group. Contrast volume to creatinine clearance ratio for the prediction of contrastinduced nephropathy in patients undergoing coronary angiography or percutaneous intervention. Eur J Prev Cardiol. 2016 Jun;23(9): 931-7.

33 Zhong SR, Teng J. Blood pressure management and acute kidney injury in perioperative period of cardiac surgery. Chin J Neph. 2018 Mar;34(3):232-5.

34 Palazzuoli A, Ruocco G, Ronco C, McCullough PA. Loop diuretics in acute heart failure: beyond the decongestive relief for the kidney. Crit Care. 2015 Sep;19(1):296.

35 Sun K, Zhao L, Mei CL. Anticoagulant associated nephropathy. Chin J Neph. 2018 Nov; 34(11):877-80.

36 Mancone M, Cavalcante R, Modolo R, Falcone M, Biondi-Zoccai G, Frati G, et al. Major infections after bypass surgery and stenting for multivessel coronary disease in the randomised SYNTAX trial. EuroIntervention. 2020 Apr;15(17):1520-6.

37 Ostermann M, Liu K. Pathophysiology of AKI. Best Pract Res Clin Anaesthesiol. 2017 Sep;31(3):305-14.

38 Faggioni M, Mehran R. Preventing contrastinduced renal failure: a guide. Interv Cardiol. 2016 Oct;11(2):98-104.

39 Chalikias G, Drosos I, Tziakas DN. Prevention of contrast-induced acute kidney injury: an update. Cardiovasc Drugs Ther. 2016 Oct; 30(5):515-24

40 Matsunami T, Hino K, Dosho R, Miyatake S, Ebisu G, Kuwatsuru R. Efficacy of oral supplemental hydration for the prevention of contrast-induced nephropathy in rats. Jpn J Radiol. 2017 Apr;35(4):190-6.

41 Cui T, Zhao J, Bei W, Li H, Tan N, Wu D, et al. Association between prophylactic hydration volume and risk of contrast-induced nephropathy after emergent percutaneous coronary intervention. Cardiol J. 2017;24(6):66070.

42 Zhang F, Lu Z, Wang F. Advances in the pathogenesis and prevention of contrast-induced nephropathy. Life Sci. 2020 Oct 15;259: 118379.

43 Stacul F, van der Molen AJ, Reimer P, Webb JA, Thomsen HS, Morcos SK, et al. Contrast induced nephropathy: updated ESUR contrast media safety committee guidelines. Eur Radiol. 2011 Dec;21(12):2527-41.

44 Abouzeid SM, ElHossary HE. Na/K citrate versus sodium bicarbonate in prevention of contrast-induced nephropathy. Saudi J Kidney Dis Transpl. 2016 May;27(3):519-25.

45 Huber W, Huber T, Baum S, Franzen M, Schmidt C, Stadlbauer T, et al. Sodium bicarbonate prevents contrast-induced nephropathy in addition to theophylline: a randomized controlled trial. Medicine. 2016 May;95(21): e3720.

46 Kooiman J, Sijpkens YW, van Buren M, Groeneveld JH, Ramai SR, van der Molen AJ, et al. Randomized trial of no hydration vs. sodium bicarbonate hydration in patients with chronic kidney disease undergoing acute computed tomography-pulmonary angiopathy. J Thromb Haemost. 2014 Oct;12(10): 1658-66.

47 Jang JS, Jin HY, Seo JS, Yang TH, Kim DK, Kim TH, et al. Sodium bicarbonate therapy for the prevention of contrast-induced acute kidney injury: a systematic review and metaanalysis. Circ J. 2012 Jun;76(9):2255-65.

48 Li XM, Jin DX, Cong HL. Could torasemide be a prophylactic agent of contrast induced acute kidney injury? A review about this field. Eur Rev Med Pharmacol Sci. 2013 Jul;17(14): $1845-9$

49 Morozova TE, Yudina IY. Selection of diuretic therapy in cardiology practice. Kardiologiia. 2016;56(9):80-3.

50 Arumugam S, Sreedhar R, Miyashita S, Karuppagounder V, Thandavarayan RA, Giridharan VV, et al. Comparative evaluation of torasemide and furosemide on rats with streptozotocin-induced diabetic nephropathy. Exp Mol Pathol. 2014 Aug;97(1):137-43.

51 Yuan Y, Qiu H, Hu XY, Luo T, Gao XJ, Zhao $\mathrm{XY}$, et al. Risk factors of contrast-induced acute kidney injury in patients undergoing emergency percutaneous coronary intervention. Chin Med J. 5 Jan 2017;130(1):45-50.

52 Tamaki S, Sato Y, Yamada T, Morita T, Furukawa Y, Iwasaki Y, et al. Tolvaptan reduces the risk of worsening renal function in patients with acute decompensated heart failure and preserved left ventricular ejection fraction: prospective randomized controlled study. Circ J. 2017 Apr;81(5):740-7.

53 Shirakabe A, Hata N, Yamamoto M, Kobayashi N, Shinada T, Tomita K, et al. Immediate administration of tolvaptan prevents the exacerbation of acute kidney injury and improves the mid-term prognosis of patients with severely decompensated acute heart failure. Circ J. 2014;78(4):911-21.

54 Matsue Y, Suzuki M, Torii S, Yamaguchi S, Fukamizu S, Ono Y, et al. Prognostic impact of early treatment with tolvaptan in patients with acute heart failure and renal dysfunction. Int J Cardiol. 2016 Oct;221:188-93.

55 Felker GM, Mentz RJ, Cole RT, Adams KF, Egnaczyk GF, Fiuzat M, et al. Efficacy and safety of tolvaptan in patients hospitalized with acute heart failure. J Am Coll Cardiol. 2017 Mar;69(11):1399-406.

56 Kostapanos MS, Liberopoulos EN, Elisaf MS. Statin pleiotropy against renal injury. J Cardiometab Syndr. 2009;4(1):E4-9.

57 Liu LY, Liu Y, Wu MY, Sun YY, Ma FZ. Efficacy of atorvastatin on the prevention of contrast-induced acute kidney injury: a metaanalysis. Drug Des Devel Ther. 2018;12:43744.

58 Liang M, Yang S, Fu N. Efficacy of short-term moderate or high-dose rosuvastatin in preventing contrast-induced nephropathy: a meta-analysis of 15 randomized controlled trials. Medicine. 2017 Jul;96(27):e7384. 
59 Wang XL, Zhang T, Hu LH, Sun SQ, Zhang WF, Sun Z, et al. Comparison of effects of different statins on contrast-induced acute kidney injury in rats: histopathological and biochemical findings. Oxid Med Cell Longev. 2017;2017:6282486.

60 Subramaniam RM, Suarez-Cuervo C, Wilson RF, Turban S, Zhang A, Sherrod C, et al. Effectiveness of prevention strategies for contrast-induced nephropathy: a systematic review and meta-analysis. Ann Intern Med. 2016 Mar;164(6):406-16.

61 Xia Q, Liu C, Zheng X. N-acetylcysteine ameliorates contrast: induced kidney injury in rats with unilateral hydronephrosis. Mol Med Rep. 2018 Feb;17(2):2203-10.

62 Garcia S, Bhatt DL, Gallagher M, Jneid H, Kaufman J, Palevsky PM, et al. Strategies to reduce acute kidney injury and improve clinical outcomes following percutaneous coronary intervention: a subgroup analysis of the PRESERVE trial. JACC Cardiovasc Interv. 2018;11(22):2254-61.
63 Weisbord SD, Gallagher M, Jneid H, Garcia S, Cass A, Thwin SS, et al. Outcomes after angiography with sodium bicarbonate and acetylcysteine. N Engl J Med. 2018;378(7):603-14.

64 Erturk M, Uslu N, Gorgulu S, Akbay E, Kurtulus G, Akturk IF, et al. Does intravenous or oral high-dose $\mathrm{N}$-acetylcysteine in addition to saline prevent contrast-induced nephropathy assessed by cystatin C? Coron Artery Dis. 2014 Mar;25(2):111-7.

65 Akgüllü Ç, Saruhan T, Eryilmaz U, Boyacıoğlu M, Onbaşılı OA, Meteoğlu İ, et al. The first histopathological evidence of trimetazidine for the prevention of contrast-induced nephropathy. Ren Fail. 2014 May;36(4):575-80.

66 Erer D, Özer A, Demirtaş H, Gönül İI, Kara $\mathrm{H}$, Arpaci $\mathrm{H}$, et al. Effects of alprostadil and iloprost on renal, lung, and skeletal muscle injury following hindlimb ischemia-reperfusion injury in rats. Drug Des Devel Ther. 2016 Aug;10:2651-8.
67 Liang M, Yang S, Fu N, Lu C, Tian F, Xing X, et al. Efficacy of alprostadil in preventing contrast-induced nephropathy in patients undergoing percutaneous coronary intervention: a multicenter prospective randomized controlled trial. Catheter Cardiovasc Interv. 2018 Mar;91(4):742-50.

68 Marenzi G, Cosentino N, Bartorelli AL. Acute kidney injury in patients with acute coronary syndromes. Heart. 2015 Nov;101(22):177885.

69 Sav T, Cecen F, Albayrak ES. The effects of ultrafiltration and diuretic therapies on oxidative stress markers in patients with cardiorenal syndrome. Minerva Urol Nefrol. 2017 Aug;69(4):400-7.

70 Jentzer JC, Bihorac A, Brusca SB, Del Rio-Pertuz G, Kashani K, Kazory A, et al. Contemporary management of severe acute kidney injury and refractory cardiorenal syndrome: JACC council perspectives. J Am Coll Cardiol. 2020;76(9):1084-101. 